\title{
Numerical investigation of MHD stagnation-point flow and heat transfer of sodium alginate non-Newtonian nanofluid
}

https://doi.org/10.1515/nleng-2018-0044

Received March 4, 2018; accepted April 7, 2018.

\begin{abstract}
A rigorous analysis of unsteady magnetohydrodynamic mixed convection and electrically conducting nanofluid model with a stretching/shrinking wedge is presented. First, the governing partial differential equations for momentum and energy conservation are converted to coupled nonlinear ordinary differential equations by means of exact similarity transformation. The homotopy analysis method (HAM) is employed to obtain the analytical approximations for flow velocity and temperature distributions of alumina-sodium alginate naofluid. The solution is found to be dependent on some parameters including the nanoparticle volume fraction, unsteadiness parameter, magnetic parameter, mixed convection parameter and the generalized prandtl number. A systematic study is carried out to illustrate the effects of these parameters on the velocity and temperature distributions. Also, the value of skin friction coefficient and local Nusselt number are compared with copper-sodium alginate and titania-sodium alginate nanofluids.
\end{abstract}

Keywords: Homotopy analysis method (HAM), Magnetic parameter, MHD flow, Nanofluid, Sodium alginate

\section{Introduction}

Nanofluid is formed by colloidal suspension of nanometersized solid particles (1-100nm diameter) into conventional liquids such as water, ethylene glycol, or oil. Firstly, the word "nanofluid" was introduced by Choi [1, 2], that represent the new class of fluid in which nanometer-scale particles are dispersed into conventional liquids. The thermal

Bhuvnesh Sharma, M.K. Paswan, Department of Mechanical Engg., National Institute of Technology, Jamshedpur-831014, Jharkhand, India

*Corresponding Author: Sunil Kumar, Department of Mathematics, National Institute of Technology, Jamshedpur-831014, Jharkhand, India, E-mail: skiitbhu28@gmail.com, skumar.math@nitjsr.ac.in conductivity of base fluid can be increased upto 40 percent with low concentration (1-5\% by volume) of nanoparticles in order to acheive higher heat transfer efficiency $[3,4]$. Xuan [3] applied the hot wire method to measure the thermal conductivity of copper-water nanofluid and found that the thermal conductivity increases upto $43 \%$ if the volume fraction of the nanoparticle increases from $2.5 \%$ to $7.5 \%$. The nanofluid is stable, however stabilizer such as oleic acid, polyvinylpyrrolidone and laurate salt is added in the nanoparticle mixture to stabilize the nanofluid $[5,6]$. Nanofluid has ability to flow through nanochannels and occurs very less pressure drop.

Stagnation point flow is due to no-slip condition in the neighborhood of solid object. The heat transfer efficiency and pressure are at its maximun value and the nanofluid is deposit on solid surface. Such flow occurs in various fluid engineering applications including submarine flow, turbo-machinery, aerofoil and oil ships. Hiemenz [7] introduced the stagnation point flow on the solid surface in the flowing condition of fluid and reduced the NavierStokes equation into non-linear ordinary differential equation using similarity transformation. The study of stagnation flow in viscous boundary-layer in two-dimensional or axisymmetric stagnation region has gained attention by several researchers which have studied in the literature [8-11]. These studies were presented the basic behavior of viscous flow in stagnation region and applicability of similarity transformation with high accurate approximations.

Mixed convection phenomena is the combination of free convection and forced convection. The attention on the studies of convective heat transfer on stretching/shrinking sheet has gained by several researchers in past decade due to important phenomena in engineering applications including solar collector, heat exchanger, nuclear reactor, gas-cooled electrical cable, thermal insulation and atmospheric boundary-layer flows. Ramachandran et al. [12] analyzed the laminar mixed convection flow for the unsteady wall temperature and showed the variation of surface heat flux for two-dimensional NavierStokes equation. Devi et al. [13] presented the study of mixed convective boundary-layer flow on vertical flat surface. Ishak et al. [14] carried out the studies on mixed con- 
vection with magnetohydrodynamic (MHD) flow on vertical surface. Later on, the same rheological problem studied for convective surface under the effect of magnetic field $[15,16]$.

The natural convective heat transfer of nonNewtonian power-law model by means of finite element method was analyzed by Beg et al. [17] and Jin et al. [18] carried out studies on Oldroyd-B and upper-convected Maxwell models using finite volume method. A well-like analytic method is the perturbation technique which frequently used in rheology problems [19]. Numerical methods such as Differential transformation method [20], Variational iteration method [21], Runge-Kutta method and finite difference techniques [22] are based on discretization technique and permit the accurate solutions only for a certain period of time and space variables. Several non-perturbative techniques have been worked out on rheological problems such as artificial small parameter [23], $\delta$-expansion method [24] and adomian decomposition method [25]. These perturbative and non-perturbative methods are incapable to adjust the convergence region and high order of a series solution. Hence, Liao [26, 27] proposed the homotopy Analysis Method (HAM) for nonlinear problems which may reduce the complexity of convergence region of series solution.

HAM overcomes the limitations of perturbation methods as it provides freedom to choose an auxiliary parameter $(\hbar)$ which leads to increase in the convergence results. The solution to a condensation film in three dimensions on an inclined rotating disk was analytically done by Rashidi et al. [28]. Ziabakhsh et al. [29] applied HAM to compute the solution of hydromagnetic viscous flow. The diverse range of rheological problems shows the capability, validity, effectiveness, flexibility and wide variety applications of HAM.

This paper deals with the use of homotopy Analysis Method (HAM) in order to compute the analytical solutions of unsteady magnetohydrodynamic (MHD) and mixed convection nanofluid model over a stretching/shrinking wedge. Also, the influence of various parameters viz. nanoparticle volume fraction, unsteadiness parameter, magnetic parameter, mixed convection parameter and the generalized prandtl number ( $p r$ ) are analyzed on the velocity and temperature distributions for aluminasodium alginate nanofluid. The values of skin-friction coefficient and local Nusselt number for alumina-sodium alginate nanofluid are tabulated with different Prandtl number and and compared from sodium alginate nanofluids with nanoparticle copper $(\mathrm{Cu})$ and titanium dioxide $\left(\mathrm{TiO}_{2}\right)$. The residual error illustrates the simplicity and accuracy of
HAM. The residual error illustrates the simplicity and accuracy of HAM.

\section{Problem statement and mathematical model}

In this manuscript, we consider the unsteady twodimensional viscous flow over a stretching/shrinking wedge of electrically conducting and incompressible nanofluid with magnetic field effect. The $x$ axis is measured along the normal of wedge and in positive direction from the wedge to the nanofluid whereas $y$ axis is considered along the wedge surface. The flow velocity is considered by $V_{\infty}=b y /(1-a t)$ and the stretching/shrinking velocity of wedge is assumed by $v_{w}(y, t)=c y /(1-a t)$, where $c$ denotes the stretching/shrinking rate with $c<0$ or $c>0$ for shrinking or stretching wedge surface condition respectively, $b$ is constant and $a>0$ shows the stagnation flow strength. The surface temperature $\left(T_{w}\right)$ is defined as $T_{w}(y, t)=T_{\infty}+T_{0} y /(1-a t)^{2}$. Lok et al. [30] showed that the assisting flow occurs due to the heated upper half plate and the reason of opposing flow is cooled lower half plate. That's why the flow move upward near the heated wedge and tends to move down near the cooled wedge, see Figure 1.

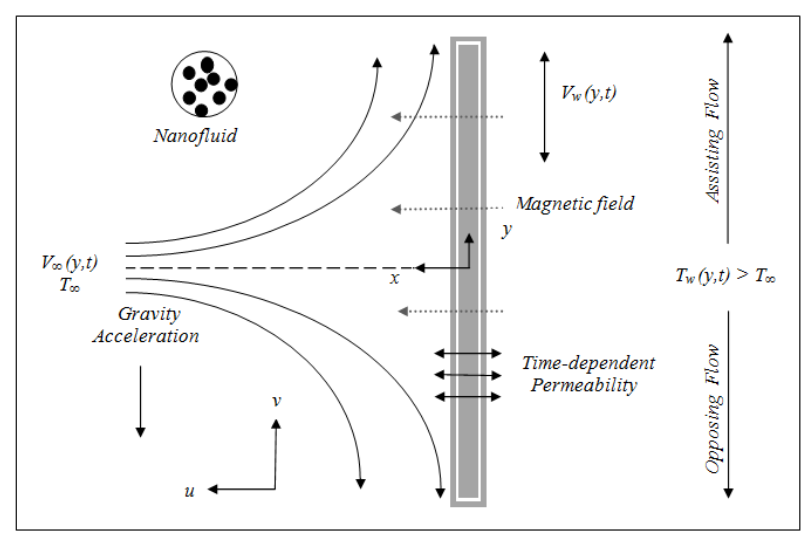

Fig. 1: Coordinate system of flow configuration.

Tiwari and Das [31] presented the MHD nanofluid model with the assumption that the base fluid (sodium alginate) is in thermal equilibrium with nanoparticle, the governing equations for mass, momentum and energy in cartesian coordinates are

$$
\frac{\partial u}{\partial x}+\frac{\partial v}{\partial y}=0,
$$


Table 1: Thermophysical properties of base fluid and nanoparticles [32].

\begin{tabular}{cccccc}
\hline Base fluid and nanoparticles & $\begin{array}{c}C_{p} \\
(\mathrm{~J} / \mathrm{Kg} \mathrm{K})\end{array}$ & $\begin{array}{c}\rho \\
\left(\mathrm{Kg} / \mathrm{m}^{3}\right)\end{array}$ & $\begin{array}{c}k \\
(\mathrm{~W} / \mathrm{m} \mathrm{K})\end{array}$ & $\begin{array}{c}\alpha \times 10^{7} \\
\left(\mathrm{~m}^{2} / \mathrm{s}\right)\end{array}$ & $\begin{array}{c}\beta \times 10^{-5} \\
(1 / \mathrm{K})\end{array}$ \\
\hline Sodium Alginate $\left(\mathrm{C}_{6} \mathrm{H}_{9} \mathrm{NaO}_{7}\right)$ & 4175 & 989 & 0.6376 & 1.62 & 23 \\
Copper $(\mathrm{Cu})$ & 385 & 8933 & 400 & 1163.1 & 1.67 \\
Titanium dioxide $\left(\mathrm{TiO}_{2}\right)$ & 686.2 & 4250 & 8.954 & 30.7 & 0.9 \\
Alumina $\left(\mathrm{Al}_{2} \mathrm{O}_{3}\right)$ & 765 & 3970 & 40 & 131.7 & 0.85 \\
\hline
\end{tabular}

$$
\begin{gathered}
\frac{\partial v}{\partial t}+u \frac{\partial u}{\partial x}+v \frac{\partial v}{\partial y}=\frac{\mu_{n f}}{\rho_{n f}} \frac{\partial^{2} v}{\partial x^{2}}-\frac{1}{\rho_{n f}} \frac{d p}{d y}-\frac{\sigma F^{2}}{\rho_{n f}} v \\
+\frac{\phi \rho_{s} \beta_{s}+(1-\phi) \rho_{f} \beta_{f}}{\rho_{n f}} a_{g}\left(T-T_{\infty}\right), \\
\frac{\partial T}{\partial t}+v \frac{\partial T}{\partial y}+u \frac{\partial T}{\partial x}=\alpha_{n f} \frac{\partial^{2} T}{\partial x^{2}},
\end{gathered}
$$

The appropriate boundary conditions are

$$
\begin{aligned}
& t<0: u=v=0, \quad T=T_{\infty}, \quad \text { for any } x, y, \\
& t \geq 0: \quad v=v_{w}(y, t), \quad u=U_{w}^{\star}(t), \quad T=T_{w}(y, t) \text { at } x=0, \\
& x \rightarrow 0: \quad v \rightarrow v_{\infty}(y, t), \quad T \rightarrow T_{\infty} .
\end{aligned}
$$

Using generalized Bernoulli's equation, Eq. (2) will be as follows

$$
\frac{d v_{\infty}}{d t}+v_{\infty} \frac{d v_{\infty}}{d y}=-\frac{1}{\rho_{n f}} \frac{d p}{d y}-\frac{\sigma F^{2}}{\rho_{n f}} v_{\infty}
$$

By substituting Eq. (5), Eq. (2) can be presented as

$$
\begin{aligned}
& \frac{\partial v}{\partial t}+u \frac{\partial u}{\partial x}+v \frac{\partial v}{\partial y}=\frac{\mu_{n f}}{\rho_{n f}} \frac{\partial^{2} v}{\partial x^{2}}+\frac{d v_{\infty}}{d t}+v_{\infty} \frac{d v_{\infty}}{d y} \\
& +\frac{\sigma F^{2}}{\rho_{n f}}\left(v_{\infty}-v\right)+\frac{\phi \rho_{s} \beta_{s}+(1-\phi) \rho_{f} \beta_{f}}{\rho_{n f}} a_{g}\left(T-T_{\infty}\right) .
\end{aligned}
$$

The velocity components are denoted by $u$ and $v$ along $x$ and $y$ axis respectively. Magnetic field applied along $x$ axis. The thermal expansion coefficients of solid nanoparticle and base fluid are showed by $\beta_{s}$ and $\beta_{f}$ respectively. The uniform surface mass flux $U_{w}^{\star}$ corresponds to suction, injection and impermeable surface for the case $U_{w}^{\star}<0$, $U_{w}^{\star}>0$ and $U_{w}^{\star}>0$ respectively. The viscosity $\left(\mu_{n f}\right)$, thermal diffusivity $\left(\alpha_{n f}\right)$, density $\left(\rho_{n f}\right)$ and heat capacitance $\left(\rho C_{p}\right)_{n f}$ of nanofluid are defined as

$$
\begin{gathered}
\mu_{n f}=\frac{\mu_{f}}{(1-\phi)^{2.5}}, \\
\rho_{n f}=(1-\phi) \rho_{f}+\phi \rho_{s}, \\
\left(\rho C_{p}\right)_{n f}=(1-\phi)\left(\rho C_{p}\right)_{f}+\phi\left(\rho C_{p}\right)_{s},
\end{gathered}
$$

$$
\alpha_{n f}=\frac{k_{n f}}{\left(\rho C_{p}\right)_{n f}},
$$

The thermal conductivity of nanofluid $\left(k_{n f}\right)$ are given by Maxwell-Garnett model [32], which is presented as follows

$$
\frac{k_{n f}}{k_{f}}=\frac{\left(k_{s}+2 k_{f}\right)-2 \phi\left(k_{f}-k_{s}\right)}{\left(k_{s}+2 k_{f}\right)+\phi\left(k_{f}-k_{s}\right)},
$$

where $\phi$ shows the solid volume fraction of nanofluid, $\rho_{f}$ and $\rho_{s}$ are the density of base fluid and solid nanoparticle respectively, $\mu_{f}$ is the viscosity of base fluid, $k_{f}$ and $k_{s}$ are the thermal conductivity of base fluid and nanoparticle respectively.

The development process of this model exhibit the transformation of governing equations to $\eta$, $\xi$ system. The similar variable $\eta$ involves both $x$ and $y$, while $\xi$ is related to $x$ alone. Therefore, we assume $\xi=0$ for any stream-wise location and $f$ is the function of only variable $\eta$. To proceed, we adopt the following similarity transformations. The physical stream function is introduced as

$$
\psi=\left(\frac{b u_{f}}{1-a t}\right)^{1 / 2} y f(\eta)
$$

The dimensionless temperature is defined as

$$
\theta(\eta)=\frac{T-T_{\infty}}{T_{w}-T_{\infty}} .
$$

The transformed similar variable is

$$
\eta=\left(\frac{b}{u_{f}(1-a t)}\right)^{1 / 2} x .
$$

The stream function can be defined by

$$
u=\frac{\partial \psi}{\partial x}, \quad v=-\frac{\partial \psi}{\partial y} .
$$

Using stream function, the velocity component $u$ and $v$ can be derived as follows

$$
\begin{gathered}
u=-\left(\frac{u b}{1-a t}\right)^{1 / 2} f(\eta), \\
v=\frac{b y}{1-a t} f^{\prime}(\eta)=V_{\infty}(y, t) f^{\prime}(\eta) .
\end{gathered}
$$


The surface mass flux $U_{w}^{\star}$ is transformed in term of wall transpiration parameter:

$$
U_{w}^{\star}=-\left(\frac{u b}{1-c t}\right)^{1 / 2} U_{w} .
$$

The mass conservation equation (1) is identically satisfied with stream function. Under the transformation (7)(18), the momentum equation (6) and energy conservation equation (3) reduce to the following nonlinear ordinary differential equation:

$$
\begin{gathered}
\frac{1}{(1-\phi)^{2.5}\left(1-\phi+\phi \frac{\rho_{s}}{\rho_{f}}\right)} f^{\prime \prime \prime}+f^{\prime \prime}-f^{\prime 2}+1+A\left(1-f^{\prime}-\frac{1}{2} \eta f^{\prime \prime}\right) \\
+\frac{M}{\left(1-\phi+\phi \frac{\rho_{s}}{\rho_{f}}\right)}\left(1-f^{\prime}\right)+\frac{1-\phi+\phi\left(\frac{\rho_{s}}{\rho_{f}}\right)\left(\frac{\beta_{s}}{\beta_{f}}\right)}{1-\phi+\phi \frac{\rho_{s}}{\rho_{f}}} \lambda \theta=0,
\end{gathered}
$$

$$
\frac{\frac{k_{n f}}{k_{f}}}{(1-\phi)+\phi \frac{\left(\rho C_{p}\right)_{s}}{\left(\rho C_{p}\right)_{f}}} \theta^{\prime \prime}+\operatorname{Pr}\left(f \theta^{\prime}-\theta f^{\prime}-A\left(2 \theta+\frac{1}{2} \eta \theta^{\prime}\right)\right)=0,
$$

which are subjected to the transformed boundary conditions:

$$
\begin{gathered}
\eta \rightarrow 0: f=U_{w}, f^{\prime}=c / b=\varepsilon, \quad \eta \rightarrow \infty: f^{\prime}=1, \\
\theta \rightarrow 0: \theta=1 \quad \eta \rightarrow \infty: \theta=0,
\end{gathered}
$$

where $\operatorname{Pr}=v_{f} / \alpha_{f}$ is the Prandtl number and magnetic parameter is defined as $M=\sigma F^{2} / \rho_{f} b$. The unsteadiness parameter $(A=a / b)$ shows positive and negative acceleration for the case $A>0$ and $A<0$ respectively. The ratio of stretching/shrinking rate wedge and strength of stagnation flow is denoted by velocity ratio parameter $(\epsilon)$, which presents $\epsilon>0, \epsilon<0$ and $\epsilon=1$ for stretching wedge, shrinking wedge and flow without boundary layer $\left(v_{w}=V_{\infty}\right)$ respectively. Mixed convection parameter $(\lambda)$ corresponds to assisting and opposing flow with conditions $\lambda>0$ and $\lambda<0$ respectively. It should be noticed that $\lambda=0$ shows the forced convection or absence of buoyancy force condition, $\phi=0$ for pure base fluid, $\epsilon=0$ for stationary wedge, $M=0$ with negligible magnetic effect, $A=0$ shows steady state flow and $U_{w}=0$ for impermeable plate.

The buoyancy or mixed convection parameter $(\lambda)$, local Grashof number $\left(G r_{y}\right)$ and Reynold number $\left(R_{y}\right)$ are defined as

$$
\begin{gathered}
\lambda=\frac{G r_{y}}{R e_{y}}=a_{g} \beta_{f} c / b^{2}, \\
G r_{y}=a_{g} \beta_{f}\left(T_{w}-T_{\infty}\right) \frac{y^{3}}{v_{f}^{2}},
\end{gathered}
$$

$$
\operatorname{Re}_{y}=\frac{V_{\infty} y}{v_{f}} .
$$

The skin-friction coefficient is defined as

$$
C_{f}=\frac{\tau_{w}}{\rho_{f} v^{2} / 2}
$$

and the local Nusselt number is defined as

$$
N u_{y}=\frac{y Q_{w}}{k_{f}\left(T_{w}-T_{\infty}\right)},
$$

where the wall shear stress $\left(\tau_{w}\right)$ can be written as

$$
\tau_{w}=\mu_{n f}\left(\frac{\partial v}{\partial x}\right)_{x=0}
$$

and the heat flux $\left(Q_{w}\right)$ is

$$
Q_{w}=-k_{n f}\left(\frac{\partial T}{\partial x}\right)_{x=0} .
$$

Using similarity variables Eq. (12)-(17), the skin-friction coefficient and Nusselt number can be presented in the form

$$
\begin{gathered}
C_{f}\left[R e_{y}\right]^{1 / 2}=\frac{1}{(1-\phi)^{2.5}} f^{\prime \prime}(0), \\
N u_{y}\left[R e_{y}\right]^{-1 / 2}=-\frac{k_{n f}}{k_{f}} \theta^{\prime}(0) .
\end{gathered}
$$

\section{Basic idea of HAM}

Let us consider the nonlinear differential equation,

$$
N[x(t)]=0,
$$

where $N$ is a nonlinear operator, $t$ is an independent variable and $x(t)$ is the solution of equation. The function $\phi(t, q)$ is introduce as

$$
\lim \phi(t, \underset{q \rightarrow 0}{q})=x_{0}(t),
$$

where $q \in[0,1]$ denotes the embedding parameter and $x_{0}(t)$ shows the initial approximation which fulfills the primary condition and the solution of equation is

$$
\lim \phi(t, \underset{q \rightarrow 1}{q})=x(t) .
$$

Using the Liao's homotopy Analysis Method (HAM), the zeroth-order deformation equation,

$$
(1-q) \mathcal{L}\left[\phi(t, q)-x_{0}(t)\right]=q \hbar \mathcal{H}(t) N[\phi(t, q)],
$$

where $\hbar$ is convergence-control parameter, $\mathcal{H}(t)$ is the auxiliary function and $\mathcal{L}$ is the linear operator. HAM provides 
a way to select auxiliary parameter $\hbar$, auxiliary function $\mathcal{H}(t)$, initial approximation $x_{0}(t)$ and linear operator $\mathcal{L}$ as the HAM establishes a promise to evaluate solutions with high accuracy. When the $q$ increases from 0 to 1 , the solution $\phi(t, q)$ varies from initial approximation $x_{0}(t)$ to the solution $x(t)$. Then, $x(t, q)$ can be express in the form of Taylor series as

$$
\phi(t, q)=x_{0}(t)+\sum_{m=1}^{\infty} x_{(t)} q^{m}
$$

and

$$
x_{0}^{[m]}(t)=\left.\frac{\partial^{m} \phi(t ; q)}{\partial q^{m}}\right|_{q=0},
$$

where

$$
x_{0}(t)=\frac{\chi_{0}^{[m]}}{m !}=\left.\frac{1}{m !} \frac{\partial^{m} \phi(t ; q)}{\partial q^{m}}\right|_{q=0} .
$$

Now, introducing the vector expression,

$$
\vec{x}_{m}=\left\{\vec{x}_{1}, \vec{x}_{2}, \vec{x}_{3} \ldots \ldots, \vec{x}_{m}\right\} .
$$

Differentiating Eq. (30) for $m$ times w.r.t. $q$, put $q=0$ and divide by $m$ !, we will obtain the $m$-th order deformation equation,

$$
\mathcal{L}\left[x_{m}(t)-\chi_{m} x_{m-1}(t)\right]=\hbar \mathcal{H}(t) R\left(\vec{x}_{m-1}\right),
$$

where

$$
R_{m}\left(\vec{x}_{m-1}\right)=\left.\frac{1}{(m-1) !} \frac{\partial^{m-1} N[\phi(t ; q)]}{\partial q^{m-1}}\right|_{q=0}
$$

and

$$
\chi_{m}=\left\{\begin{array}{ll}
0, & m \leq 1 \\
1 & m>1
\end{array} .\right.
$$

Using the inverse linear operator in Eq. (30), we can compute the solution of equations in simplified way.

\section{HAM Solutions}

The initial guess $f(\eta)$ and $\theta(\eta)$ of the transformed Eqs. (19) and (20) are choosen for HAM solutions as follows

$$
\begin{gathered}
f_{0}(\eta)=U_{w}-(1-\varepsilon)+\eta+(1-\varepsilon) e^{-\eta}, \\
\theta_{0}(\eta)=e^{-\eta}
\end{gathered}
$$

and we consider the linear operators:

$$
\mathcal{L}_{f}=\frac{\partial^{3} f}{\partial \eta^{3}}-\frac{\partial f}{\partial \eta},
$$

$$
\mathcal{L}_{\theta}=\frac{\partial^{2} \theta}{\partial \eta^{2}}-\theta
$$

Introducing a embedding parameter $q \in[0,1]$ and convergence-control parameter $\hbar$, the zeroth-order deformation equations can be written as

$$
\begin{aligned}
& (1-q) \mathcal{L}_{f}\left[f(\eta ; q)-f_{0}(\eta)\right]=q \hbar \mathcal{H}_{f}(\eta) N_{f}[f(\eta ; q)], \\
& f(0 ; q)=U_{w}, \quad f^{\prime}(0 ; q)=\varepsilon, \quad f^{\prime}(\infty ; q)=1,
\end{aligned}
$$

$$
(1-q) \mathcal{L}_{\theta}\left[\theta(\eta ; q)-\theta_{0}(\eta)\right]=q \hbar \mathcal{H}_{\theta}(\eta) N_{\theta}[\theta(\eta ; q)],
$$

$$
\theta(0 ; q)=1, \quad \theta^{\prime}(\infty ; q)=0 .
$$

In which the nonlinear operators are presented as

$$
\begin{aligned}
N_{f}= & \frac{1}{(1-\phi)^{2.5}\left(1-\phi+\phi \frac{\rho_{s}}{\rho_{f}}\right)}\left(\frac{\partial^{3} f(\eta ; q)}{\partial \eta^{3}}\right) \\
& +f(\eta ; q)\left(\frac{\partial^{2} f(\eta ; q)}{\partial \eta^{2}}\right)-\left(\frac{\partial f(\eta ; q)}{\partial \eta}\right)^{2}+\left(1-\chi_{m}\right) \\
& +A\left(1-\frac{\partial f(\eta ; q)}{\partial \eta}-\frac{1}{2} \eta \frac{\partial^{2} f(\eta ; q)}{\partial \eta^{2}}-\chi_{m}\right) \\
& +\frac{M}{\left(1-\phi+\phi \frac{\rho_{s}}{\rho_{f}}\right)}\left(1-\frac{\partial f(\eta ; q)}{\partial \eta}\right) \\
& +\frac{1-\phi+\phi\left(\frac{\rho_{s}}{\rho_{f}}\right)\left(\frac{\beta_{s}}{\beta_{f}}\right)}{1-\phi+\phi \frac{\rho_{s}}{\rho_{f}}} \lambda \theta(\eta ; q),
\end{aligned}
$$

$$
\begin{aligned}
N_{\theta}= & \frac{\frac{k_{n f}}{k_{f}}}{(1-\phi)+\phi \frac{\left(\rho C_{p}\right)_{s}}{\left(\rho C_{p}\right)_{f}}}\left(\frac{\partial^{2} \theta(\eta ; q)}{\partial \eta^{2}}\right) \\
& +\operatorname{Pr}\left(f(\eta ; q) \frac{\partial \theta(\eta ; q)}{\partial \eta}-\theta(\eta ; q) \frac{\partial f(\eta ; q)}{\partial \eta}\right. \\
& \left.-A\left(2 \theta(\eta ; q)+\frac{1}{2} \eta \frac{\partial \theta(\eta ; q)}{\partial \eta}\right)\right),
\end{aligned}
$$

For $q=0$ and $q=1$, we have respectively

$$
q=0: \quad f(\eta ; 0)=f_{0}(\eta), \quad \theta(\eta ; 0)=\theta_{0}(\eta),
$$

$$
q=1: \quad f(\eta ; 1)=f(\eta), \quad \theta(\eta ; 1)=\theta(\eta) .
$$

$f(\eta ; p)$ varies from $f_{0}(\eta)$ to $f(\eta)$ and $\theta(\eta ; p)$ varies from $\theta_{0}(\eta)$ to $\theta(\eta)$, when $q$ increases from 0 to 1 . Using Eqs. (51)(52) and Taylor's theorem, $f(\eta ; q)$ and $\theta(\eta ; q)$ can be presented in a power series form

$$
f(\eta ; q)=f_{0}(\eta)+\sum_{m=1}^{\infty} f_{m}(\eta) q^{m},
$$




$$
f_{m}(\eta)=\left.\frac{1}{m !} \frac{\partial^{m} f(\eta ; q)}{\partial q^{m}}\right|_{q=0}
$$

and

$$
\begin{gathered}
\theta(\eta ; q)=\theta_{0}(\eta)+\sum_{m=1}^{\infty} \theta_{m}(\eta) q^{m}, \\
\theta_{m}(\eta)=\left.\frac{1}{m !} \frac{\partial^{m} \theta(\eta ; q)}{\partial q^{m}}\right|_{q=0} .
\end{gathered}
$$

In which the auxiliary parameter $\hbar$ is selected such the series is convergent at $q=1$. Liao [26] pointed out that the convergence-region depends on a convergence-control parameter $\hbar$. Then, Eqs. (53) and (55) are as follows

$$
\begin{aligned}
& f(\eta)=f_{0}(\eta)+\sum_{m=1}^{\infty} f_{m}(\eta), \\
& \theta(\eta)=\theta_{0}(\eta)+\sum_{m=1}^{\infty} \theta_{m}(\eta) .
\end{aligned}
$$

The $m$ th-order deformation equations:

$$
\begin{gathered}
\mathcal{L}\left[f_{m}(\eta)-\chi_{m} f_{m-1}(\eta)\right]=\hbar \mathcal{H}_{f}(\eta) R_{m}^{f}(\eta), \\
\mathcal{L}\left[\theta_{m}(\eta)-\chi_{m} \theta_{m-1}(\eta)\right]=\hbar \mathcal{H}_{\theta}(\eta) R_{m}^{\theta}(\eta), \\
\eta=0: f_{m}=U_{w}, f_{m}^{\prime}=\varepsilon, \quad \eta=\infty: f_{m}=1, \\
\theta=0: \theta_{m}=1, \quad \theta=\infty: \theta_{m}=0,
\end{gathered}
$$

where $R_{m}^{f}(\eta)$ and $R_{m}^{\theta}(\eta)$ are defined as

$$
\begin{aligned}
& R_{m}^{f}(\eta)=\frac{1}{(1-\phi)^{2.5}\left(1-\phi+\phi \frac{\rho_{s}}{\rho_{f}}\right)}\left(\frac{\partial^{3} f_{m-1}(\eta ; q)}{\partial \eta^{3}}\right) \\
& +\sum_{n=0}^{m-1}\left[f_{n}(\eta ; q) \frac{\partial^{2} f_{m-1-n}(\eta ; q)}{\partial \eta^{2}}-\frac{\partial f_{n}(\eta ; q)}{\partial \eta} \frac{\partial f_{m-1-n}(\eta ; q)}{\partial \eta}\right] \\
& +\left(1-\chi_{m}\right)+A\left(1-\frac{\partial f_{m-1}(\eta ; q)}{\partial \eta}-\frac{1}{2} \eta \frac{\partial^{2} f_{m-1}(\eta ; q)}{\partial \eta^{2}}-\chi_{m}\right) \\
& +\frac{M}{\left(1-\phi+\phi \frac{\rho_{s}}{\rho_{f}}\right)}\left(1-\frac{\partial f_{m-1}(\eta ; q)}{\partial \eta}\right) \\
& +\frac{1-\phi+\phi\left(\frac{\rho_{s}}{\rho_{f}}\right)\left(\frac{\beta_{s}}{\beta_{f}}\right)}{1-\phi+\phi \frac{\rho_{s}}{\rho_{f}}} \lambda \theta_{m-1}(\eta ; q),
\end{aligned}
$$

$$
\begin{aligned}
& R_{m}^{\theta}(\eta)=\frac{\frac{k_{n f}}{k_{f}}}{(1-\phi)+\phi \frac{\left(\rho C_{p}\right)_{s}}{\left(\rho C_{p}\right)_{f}}}\left(\frac{\partial^{2} \theta_{m-1}(\eta ; q)}{\partial \eta^{2}}\right) \\
& +\operatorname{Pr}\left(\sum_{n=0}^{m-1}\left[f_{n}(\eta ; q) \frac{\partial \theta_{m-1-n}(\eta ; q)}{\partial \eta}-\frac{\partial f_{n}(\eta ; q)}{\partial \eta} \theta_{m-1-n}(\eta ; q)\right]\right. \\
& \left.-A\left(2 \theta_{m-1}(\eta ; q)+\frac{1}{2} \eta \frac{\partial \theta_{m-1}(\eta ; q)}{\partial \eta}\right)\right) .
\end{aligned}
$$

we consider the auxiliary function as $\mathcal{H}_{f}(\eta), \mathcal{H}_{\theta}(\eta)=1$. The calculation are made for sodium alginate nanofluid with alumina as nanoparticle with $P r=6.2$ as considered in Tiwari and Das [31] nanofluid model. The parameters of nanofluid are assumed as $A=0.5, \lambda=1, M=1, U_{w}=0.5$ and $\phi=0.2$ to obtain the solution of coupled equations with appropriate boundary conditions.

$$
\begin{gathered}
f_{1}(\eta)=-0.5+e^{-\eta}-1.5892 \hbar+1.5892 e^{-\eta} \hbar \\
+1.5892 e^{-\eta} \hbar \eta+0.1875 e^{-\eta} \hbar \eta^{2}, \\
\theta_{1}(\eta)=e^{-\eta}+4.9092 e^{-\eta} \hbar \eta+1.1625 e^{-\eta} \hbar \eta^{2},
\end{gathered}
$$

$$
\begin{aligned}
f_{2}(\eta)= & -1.5892 \hbar+1.5892 e^{-\eta} \hbar-7.5388 \hbar^{2} \\
& -0.0625 e^{-2 \eta} \hbar^{2}+7.6013 e^{-\eta} \hbar^{2}+1.5892 e^{-\eta} \hbar \eta \\
& +7.4763 e^{-\eta} \hbar^{2} \eta+0.1875 e^{-\eta} \hbar \eta^{2}+2.6405 e^{-\eta} \hbar^{2} \eta^{2} \\
& +0.35925 e^{-\eta} \hbar^{2} \eta^{3}+0.0175 e^{-\eta}, \hbar^{2} \eta^{4}
\end{aligned}
$$

$$
\begin{aligned}
\theta_{2}(\eta)= & 12.234 e^{-2 \eta} \hbar^{2}-12.234 e^{-\eta} \hbar^{2}+4.9092 e^{-\eta} \hbar \eta \\
& +4.03 e^{-2 \eta} \hbar^{2} \eta+24.0522 e^{-\eta} \hbar^{2} \eta+1.1625 e^{-\eta} \hbar \eta^{2} \\
& +14.6007 e^{-\eta} \hbar^{2} \eta^{2}+4.806 e^{-\eta} \hbar^{2} \eta^{3} \\
& +0.6757 e^{-\eta} \hbar^{2} \eta^{4},
\end{aligned}
$$

Similarly, the computation of 15th order approximation of HAM are executed on MATHEMATICA 7.0 software with BVPh 2.0 package.

\section{Convergence of the HAM solutions}

The family of solutions presented by HAM is expressed in the form of an auxiliary parameter. The convergence region and rate of approximation strongly depends on the convergence-control parameter ( $\hbar$ ), as stated by Liao [27]. By means of plotting the $\hbar$-curves that represents the accepted range of $\hbar$, the convergence rate and region can be adjusted. The horizontal line segment where the series converges is the acceptable region of $\hbar$. Figures 2 depicts the $\hbar$-curves of dimensionless velocity \& temperature obtained from Eqs. (19) and (20) based on the 10th order approximation. Based on the convergence-region of $\hbar$-curves for alumina-sodium alginate nanofluid the acceptable values of $\hbar$ are tabulated in table 2 .

To find out an optimal value of an convergence-control parameter $\hbar$, the averaged residual square error can be writ- 


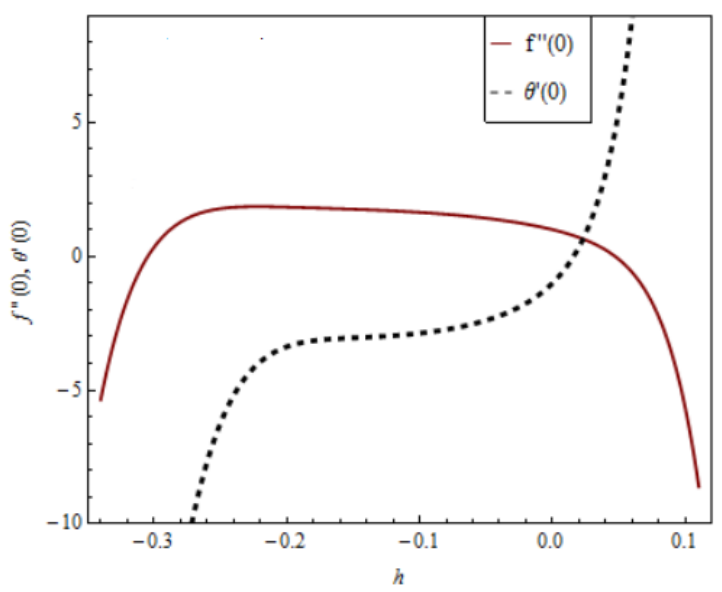

Fig. 2: The $\hbar$ curves of dimensionless velocity and dimensionless temperature for alumina-sodium alginate nanofluid with $A=0.5, M=1, U_{w}=0.5, \varepsilon=0, \operatorname{Pr}=6.2, \phi=0.2, \lambda=1$.

Table 2: Acceptable values of $\hbar$ for alumina-sodium alginate nanofluid with $A=0.5, M=1, U_{w}=0.5, \operatorname{Pr}=6.2, \phi=0.2, \lambda=1$.

\begin{tabular}{cc}
\hline Series & Acceptable Range \\
\hline$f^{\prime}(\eta)$ & $-0.25 \leq \hbar \leq-0.05$ \\
$\theta(\eta)$ & $-0.18 \leq \hbar \leq-0.1$ \\
\hline
\end{tabular}

ten as

$$
\begin{aligned}
& E_{l, f}=\frac{1}{K} \sum_{j=1}^{K}\left(N_{f}\left[\sum_{i=0}^{l} f_{i}(j \triangle x)\right]\right)^{2}, \\
& E_{l, \theta}=\frac{1}{K} \sum_{j=1}^{K}\left(N_{\theta}\left[\sum_{i=0}^{l} \theta_{i}(j \triangle x)\right]\right)^{2} .
\end{aligned}
$$

where $\Delta x=10 / K, K=20$ for transformed Eqs. (19) and (20). The optimal value of $\hbar$ is evaluated by minimizing the average residual square error $E_{m}$ corresponding to the transformed nonlinear equations

$$
\begin{aligned}
& \frac{d E_{l, f}}{d \hbar}=0, \\
& \frac{d E_{l, \theta}}{d \hbar}=0 .
\end{aligned}
$$

Table 3 exhibit the comparison of the averaged residual square error and optimal value of $\hbar$ for velocity and temperature distributions of alumina-sodium alginate nanofluid with increasing the order of approximations.

The accuracy and validity of the HAM can be demonstrated by the residual square error curves which are plotted in figure 3 and figure 4 for $f^{\prime}$ and $\theta$ with several values of auxiliary parameter for alumina-sodium alginate nanofluid.

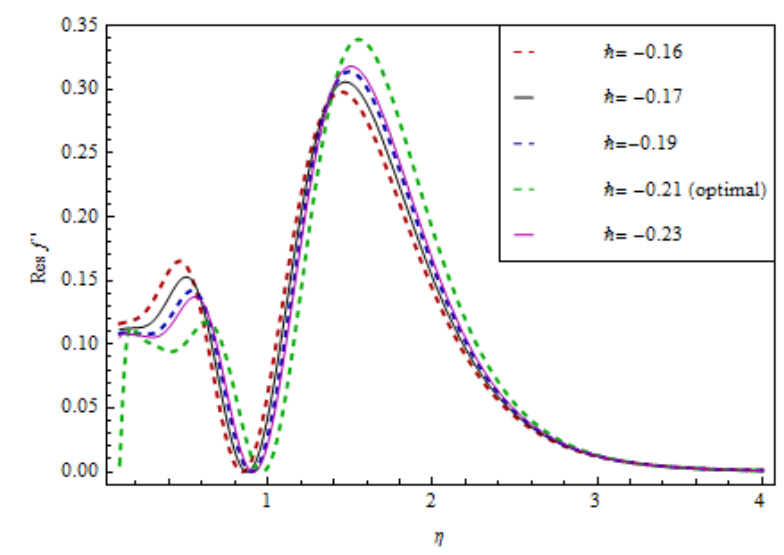

Fig. 3: Residual error for non-dimensional velocity for aluminasodium alginate nanofluid with $A=0.5, M=1, U_{w}=0.5, \operatorname{Pr}=$ $6.2, \phi=0.2, \lambda=1$.

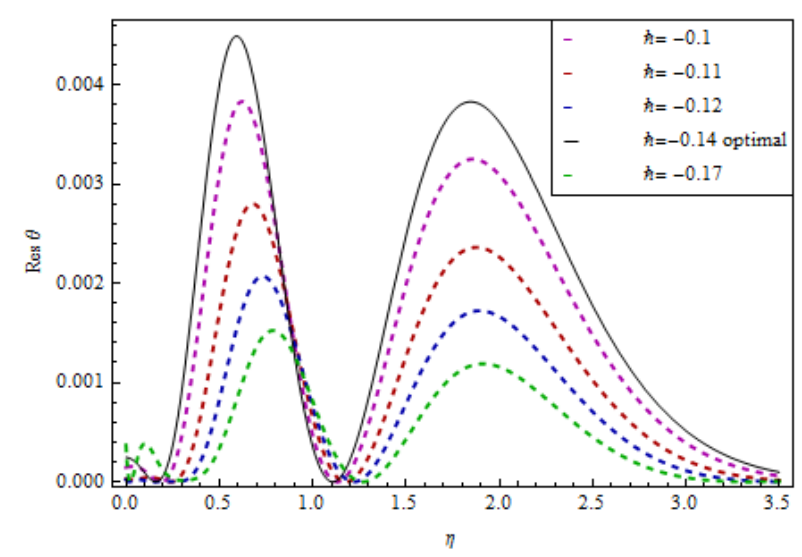

Fig. 4: Residual error for non-dimensional temperature for aluminasodium alginate nanofluid with $A=0.5, M=1, U_{w}=0.5, P r=$ 6.2, $\phi=0.2, \lambda=1$.

Table 4 exhibit the value of skin fiction coefficient and local Nusselt number for different values of Prandtl number in order to illustrate the validity and efficiency of HAM.

\section{Results and Discussion}

HAM has been effectively applied to evaluate the analytical solution for transformed nonlinear ordinary differ- 
Table 3: Optimal value of $\hbar$ for alumina-sodium alginate nanofluid with $A=0.5, M=1, U_{w}=0.5, \operatorname{Pr}=6.2, \phi=6.2, \lambda=1$.

\begin{tabular}{ccccc}
\hline & $f^{\prime}$ & $f^{\prime}$ & $\theta$ & $\theta$ \\
$N$ & Optimal value of $\hbar$ & Value of $E_{l, f}$ & Optimal value of $\hbar$ & Value of $E_{l, \theta}$ \\
\hline 1 & -0.2432 & 0.68499 & -0.1729 & $2.1767 \times 10^{-2}$ \\
2 & -0.2385 & 0.16878 & -1.31615 & $0.1735 \times 10^{-2}$ \\
3 & -0.2174 & 0.15924 & -1.38356 & $0.1587 \times 10^{-2}$ \\
\hline
\end{tabular}

$N$ - order of approximation

Table 4: The values of skin friction coefficient and local Nusselt number for alumina-sodium alginate nanofluid with various values of $P r$ when $A=0, \varepsilon=0, M=0, U_{w}=0, \phi=0, \lambda=1$.

\begin{tabular}{ccc}
\hline $\operatorname{Pr}$ & $\operatorname{Re}_{x}^{1 / 2} C_{f}$ & $N u_{x} R e_{x}^{-1 / 2}$ \\
\hline 0.7 & 1.8573 & 0.8521 \\
1 & 1.7520 & 0.8872 \\
7 & 1.7385 & 1.8036 \\
10 & 1.6214 & 2.0145 \\
20 & 1.5501 & 2.7326 \\
40 & 1.4623 & 3.2214 \\
50 & 1.3986 & 3.7048 \\
\hline
\end{tabular}

ential equations (19)-(20) describing boundary-layer flow and heat transfer for MHD mixed convection nanofluids with some values including wall transpiration parameter $\left(U_{w}\right)$, mixed convection parameter $(\lambda)$, velocity ratio parameter $(\varepsilon)$, nanoparticle volume fraction $(\phi)$, unsteadiness parameter $(A)$ and magnetic parameter $(M)$. In order to illustrates the effects of these parameters, the velocity and temperature profile has been presented from figures (5)-(16) for alumina-sodium alginate nanofluid using 15thorder of approximation. The value of Prandtl numberis considered as 6.2 (for water) and the range of nanoparticle volume fraction parameter varies from 0 (Newtonian fluid) to 0.2 as pointed out by Oztop and Abu-Nada [32]. Figure 5 and figure 6 show the velocity and temperature distributions of nanofluid respectively over a stationary surface $(\varepsilon=0)$ with variation of magnetic parameter for two values of mixed convection parameter: $\lambda=5$ (assisting flow) and $\lambda=-5$ (opposing flow). Lorentz force is produced by the application of vertical magnetic field to electrically conducting nanofluid. Lorentz force slow down the flow over the wedge which reduces the thickness of hydrodynamic boundary-layer. According to the explanation, figure 5 and figure 6 show that as the magnetic parameter increases for alumina-sodium alginate nanofluid, the velocity increases and the temperature slightly decreases respectively. Also, it can be analyzed from figures that as the positive mixed convection parameter enhances, the veloc- ity increases while the temperature of nanofluid decreases slightly.

Figure 7 and figure 8 illustrate the effects of unsteadiness parameter on the nanofluid velocity profile and temperature distribution over a stationary wedge for both opposing $\lambda>0$ and assisting flow $\lambda<0$. Figure 7 shows that increase in unsteadiness parameter $(A)$ leads to increase in velocity of nanofluid due to higher acceleration. Figure 8 reveals that the temperature increases for lower acceleration. Since the transformed equations (19)-(20) are coupled together only with the mixed convection parameter. Grashof number accelerates the fluid, so the velocity increases and temperature decreases with increase in Grashof number and mixed convection parameter.

The influence of the unsteadiness parameter and magnetic parameter on the velocity and temperature distributions for alumina-sodium alginate nanofluid are depicted from figures (9)-(12) with shrinking $(\varepsilon=-0.5)$ and stretching $(\varepsilon=0.5)$ sheet cases. Figures show the similar behaviour of thermal and boundary layer of nanofluid as described previously for figures (5)-(8). It can be analyzed that the hydrodynamic boundary-layer thickness decreases strongly for stretching sheet.

The influence of the unsteadiness parameter and magnetic parameter on the velocity and temperature distributions for alumina-sodium alginate nanofluid are depicted from figures (13)-(16) with suction $\left(U_{w}>0\right)$ and injection 


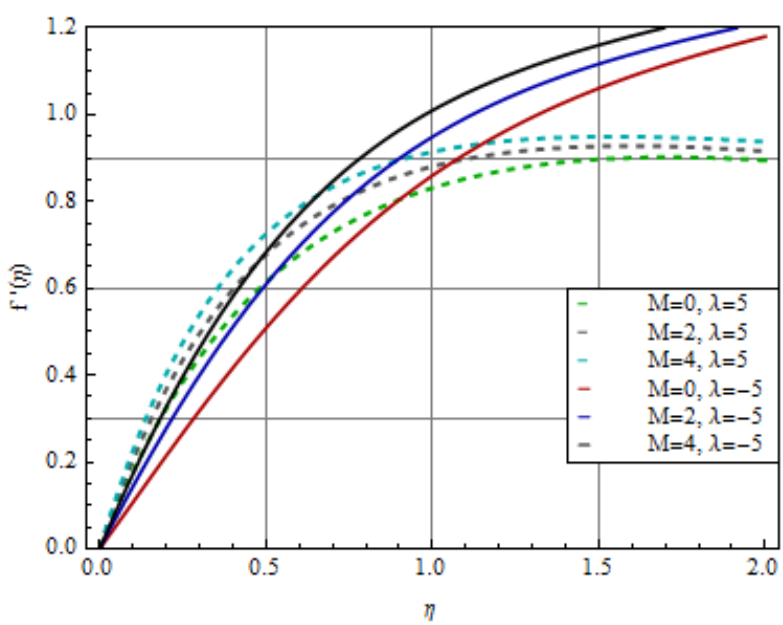

Fig. 5: The velocity distribution for alumina-sodium alginate nanofluid for different values of mixed convection and magnetic parameters with $A=0.5, U_{w}=0.5, \varepsilon=0, \operatorname{Pr}=6.2, \phi=0.2$.

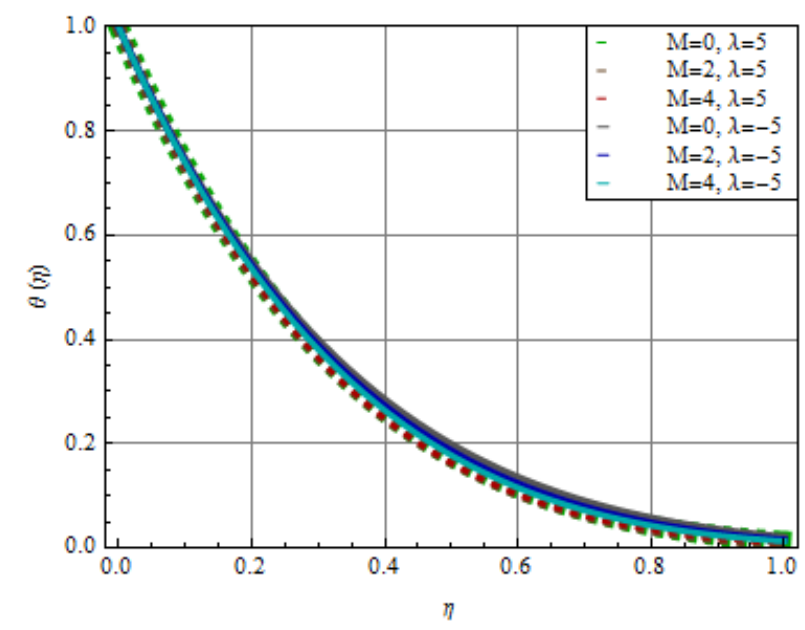

Fig. 6: The temperature distribution for alumina-sodium alginate nanofluid for different values of mixed convection and magnetic parameters with $A=0.5, U_{w}=0.5, \varepsilon=0, \operatorname{Pr}=6.2, \phi=0.2$.

$\left(U_{w}<0\right)$ cases. Figures depict the similar behaviour quality of flow characterstics as explained previously but it is worth mentioning that the thermal boundary-layer thickness decreses sensibly for suction.

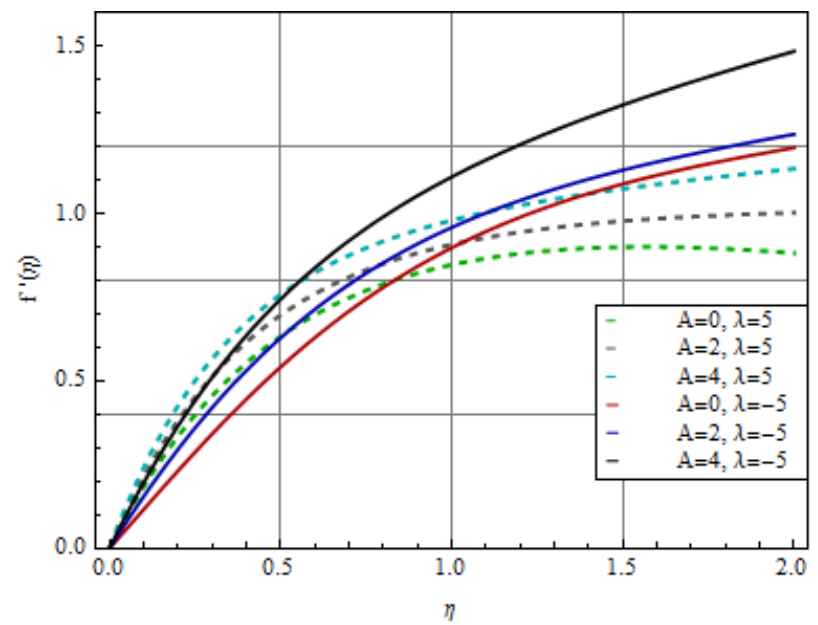

Fig. 7: The velocity distribution for alumina-sodium alginate nanofluid for different values of mixed convection and unstediness parameters with $M=1, U_{w}=0.5, \varepsilon=0, \operatorname{Pr}=6.2, \phi=0.2$.

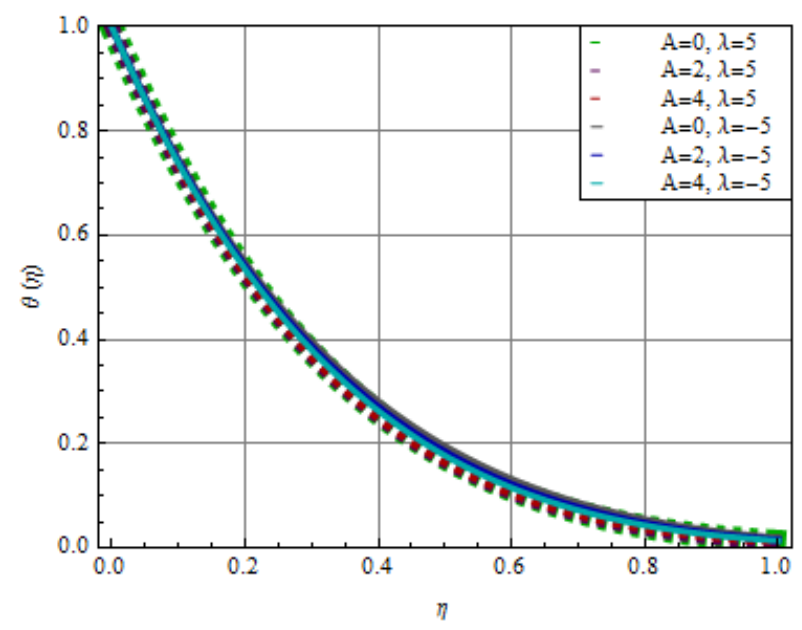

Fig. 8: The temperature distribution for alumina-sodium alginate nanofluid for different values of mixed convection and unstediness parameters with $M=1, U_{w}=0.5, \varepsilon=0, \operatorname{Pr}=6.2, \phi=0.2$. 


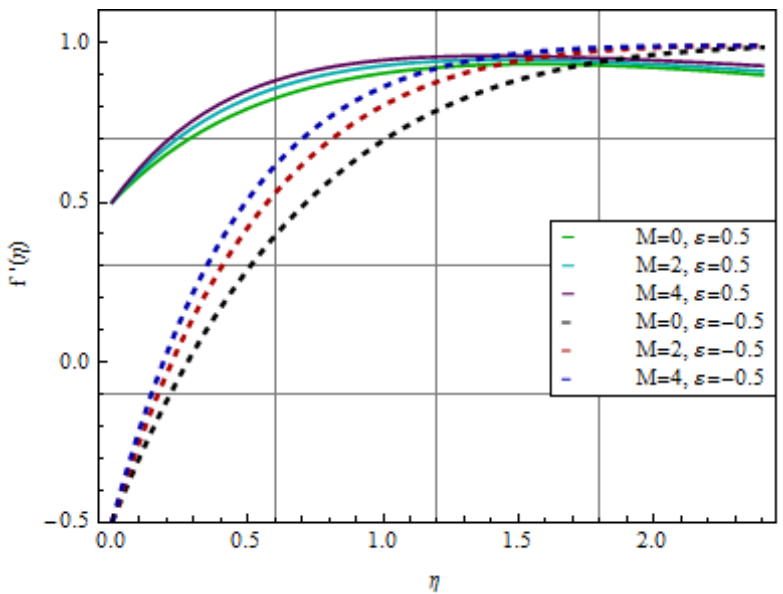

Fig. 9: The velocity distribution for alumina-sodium alginate nanofluid for different values of magnetic and velocity ratio parameters with $A=0.5, U_{w}=0.5, \lambda=1, \operatorname{Pr}=6.2, \phi=0.2$.

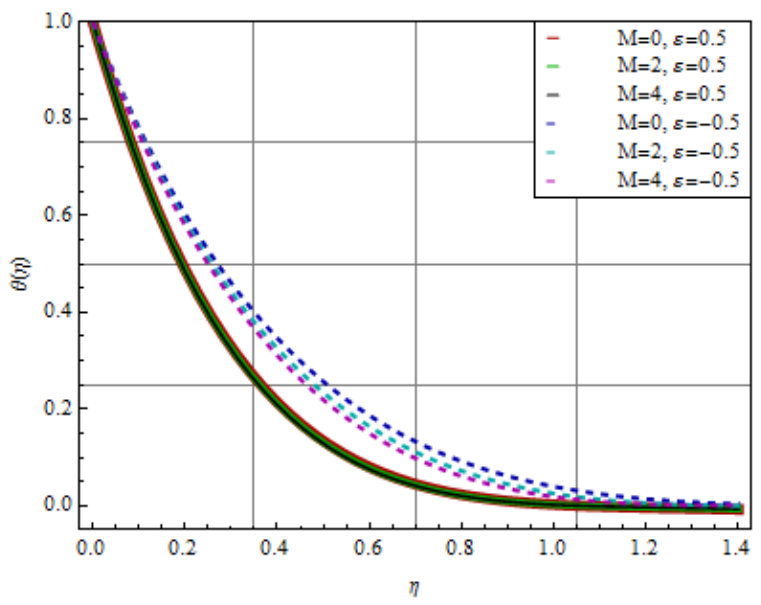

Fig. 10: The temperature distribution for alumina-sodium alginate nanofluid for different values of magnetic and velocity ratio parameters with $A=0.5, U_{w}=0.5, \lambda=1, \operatorname{Pr}=6.2, \phi=0.2$.

Table (5)-(7) present the values of skin friction coefficient and local Nusselt number with nanoparticle volume fraction $(\phi)$ in case of stretching/shrinking sheet and asssisting/opposing flows. Tables reveal that value of skin friction coefficient and local Nusselt number are higher for $\mathrm{Cu}$ as nanoparticle compared to $\mathrm{Al}_{2} \mathrm{O}_{3}$ and $\mathrm{TiO}_{2}$ nanoparticles.

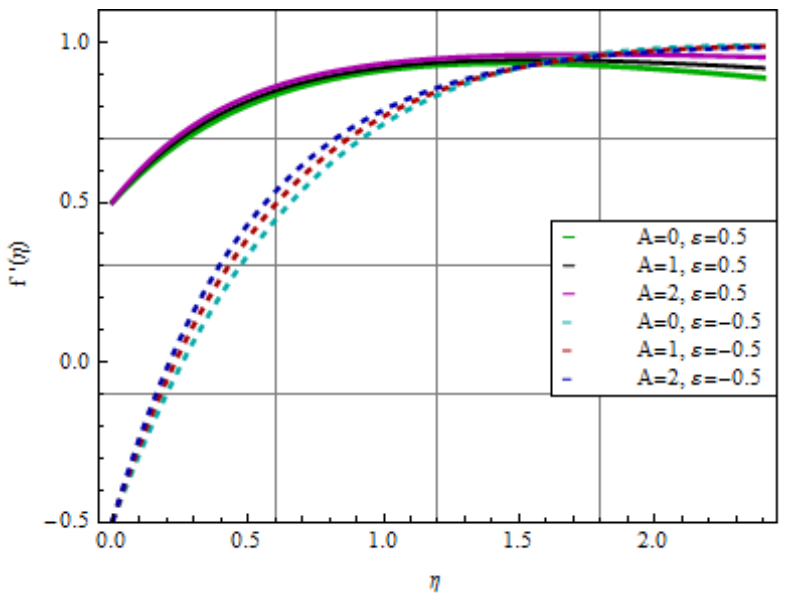

Fig. 11: The velocity distribution for alumina-sodium alginate nanofluid for different values of unsteadiness and velocity ratio parameters with $M=1, U_{w}=0.5, \lambda=1, \operatorname{Pr}=6.2, \phi=0.2$.

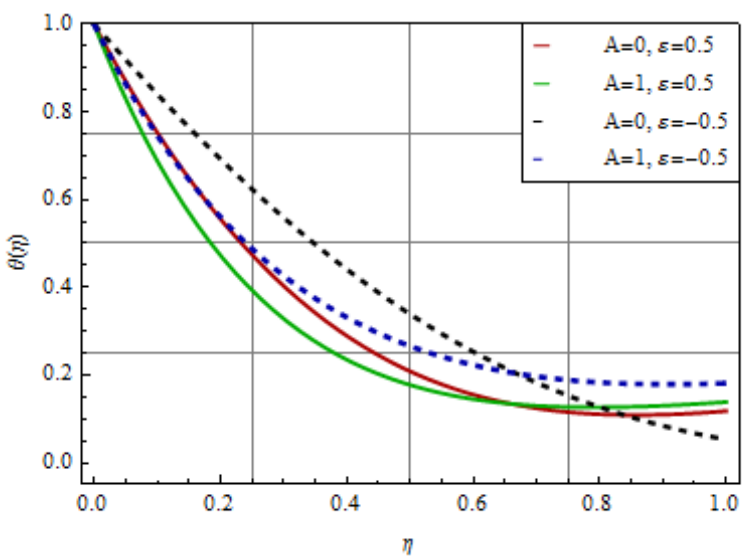

Fig. 12: The temperature distribution for alumina-sodium alginate nanofluid for different values of unsteadiness and velocity ratio parameters with $M=1, U_{w}=0.5, \lambda=1, \operatorname{Pr}=6.2, \phi=0.2$.

\section{Concluding Remarks}

Based on the results and discussions on the MHD nanofluid flow over a stretching/shrinking sheet, the following conclusions have been arrived for alumina-sodium alginate nanofluid:

- With increase in magnetic parameter as well as unsteadiness parameter, the velocity increases whereas the temperature decreases.

- With increase in Grashof number and mixed convection parameter, the temperature decreases whereas the velocity increases.

- With increase in velocity ratio parameter $(\varepsilon)$, the velocity increases whereas the temperature decreases but the magnetic parameter and unsteadiness pa- 
Table 5: The effect of the nanoparticle volume fraction on the skin friction coefficient and local Nusselt number for copper-sodium alginate nanofluid with $A=0.5, M=1, U_{w}=0.5$.

\begin{tabular}{|c|c|c|c|c|c|}
\hline \multirow[b]{2}{*}{ Parameter } & \multirow[b]{2}{*}{$\phi$} & \multicolumn{2}{|c|}{$\lambda=1$} & \multicolumn{2}{|c|}{$\lambda=-1$} \\
\hline & & $\varepsilon=-0.5$ & $\varepsilon=0.5$ & $\varepsilon=-0.5$ & $\varepsilon=0.5$ \\
\hline \multirow[t]{3}{*}{$R e_{x}^{1 / 2} C_{f}$} & 0.00 & 3.0254 & 1.7859 & 2.8435 & 1.0527 \\
\hline & 0.10 & 4.7987 & 2.0231 & 3.7231 & 1.7868 \\
\hline & 0.20 & 5.6254 & 2.8457 & 5.2428 & 2.0135 \\
\hline \multirow[t]{3}{*}{$N u_{x} R e_{x}^{-1 / 2}$} & 0.00 & 4.7135 & 5.7134 & 4.4237 & 5.5668 \\
\hline & 0.10 & 4.5387 & 6.0241 & 4.8268 & 6.0258 \\
\hline & 0.20 & 5.0264 & 6.8763 & 5.0124 & 6.7174 \\
\hline
\end{tabular}

Table 6: The effect of the nanoparticle volume fraction on the skin friction coefficient and local Nusselt number for alumina-sodium alginate nanofluid with $A=0.5, M=1, U_{w}=0.5$.

\begin{tabular}{|c|c|c|c|c|c|}
\hline \multirow[b]{2}{*}{ Parameter } & \multirow[b]{2}{*}{$\phi$} & \multicolumn{2}{|c|}{$\lambda=1$} & \multicolumn{2}{|c|}{$\lambda=-1$} \\
\hline & & $\varepsilon=-0.5$ & $\varepsilon=0.5$ & $\varepsilon=-0.5$ & $\varepsilon=0.5$ \\
\hline \multirow[t]{3}{*}{$\operatorname{Re}_{\chi}^{1 / 2} C_{f}$} & 0.00 & 3.0254 & 1.7859 & 2.8435 & 1.0527 \\
\hline & 0.10 & 4.4632 & 1.7123 & 3.4037 & 1.4478 \\
\hline & 0.20 & 4.8724 & 2.0145 & 4.9521 & 1.7137 \\
\hline \multirow[t]{3}{*}{$N u_{x} R e_{x}^{-1 / 2}$} & 0.00 & 4.7135 & 5.7134 & 4.4237 & 5.5668 \\
\hline & 0.10 & 4.3375 & 5.6214 & 4.5107 & 5.9807 \\
\hline & 0.20 & 4.8547 & 6.1114 & 4.5301 & 6.2528 \\
\hline
\end{tabular}

Table 7: The effect of the nanoparticle volume fraction on the skin friction coefficient and local Nusselt number for titania-sodium alginate nanofluid with $A=0.5, M=1, U_{w}=0.5$.

\begin{tabular}{|c|c|c|c|c|c|}
\hline \multirow[b]{2}{*}{ Parameter } & \multirow[b]{2}{*}{$\phi$} & \multicolumn{2}{|c|}{$\lambda=1$} & \multicolumn{2}{|c|}{$\lambda=-1$} \\
\hline & & $\varepsilon=-0.5$ & $\varepsilon=0.5$ & $\varepsilon=-0.5$ & $\varepsilon=0.5$ \\
\hline \multirow[t]{3}{*}{$R e_{x}^{1 / 2} C_{f}$} & 0.00 & 3.0254 & 1.7859 & 2.8435 & 1.0527 \\
\hline & 0.10 & 4.5874 & 1.9852 & 3.8737 & 1.6897 \\
\hline & 0.20 & 5.2548 & 2.2647 & 5.0021 & 1.8962 \\
\hline \multirow[t]{3}{*}{$N u_{x} R e_{x}^{-1 / 2}$} & 0.00 & 4.7135 & 5.7134 & 4.4237 & 5.5668 \\
\hline & 0.10 & 4.2958 & 5.5237 & 4.2790 & 5.7502 \\
\hline & 0.20 & 4.6250 & 6.0124 & 4.3875 & 6.0125 \\
\hline
\end{tabular}

rameter strongly affect the velocity and temperature distribution in the case of stretching sheet $(\varepsilon>0)$.

- With increase in wall surface transpiration parameter $\left(U_{w}\right)$, the velocity increases whereas the temperature decreases but the magnetic parameter and unsteadiness parameter strongly affect the velocity and temperature distribution in the case of suction $\left(U_{w}>0\right)$ compared to injection $\left(U_{w}<0\right)$.

- The tabulated results presented the highest value of skin friction and local Nusselt number for copper-sodium alginate nanofluid as compared to alumina-sodium alginate and titania-sodium alginate nanofluids.
The results show the simplicity, efficiency and accuracy of HAM for evaluating various kind of rheological problems arising in fluid dynamics.

\section{Nomenclature}

$\begin{array}{ll}A & \text { unsteadiness parameter } \\ a, b, c & \text { constant } \\ a_{g} & \text { acceleration due to gravity } \\ C_{f} & \text { skin-friction coefficient } \\ F & \text { magnetic field } \\ f(\eta) & \text { dimensionless stream function }\end{array}$




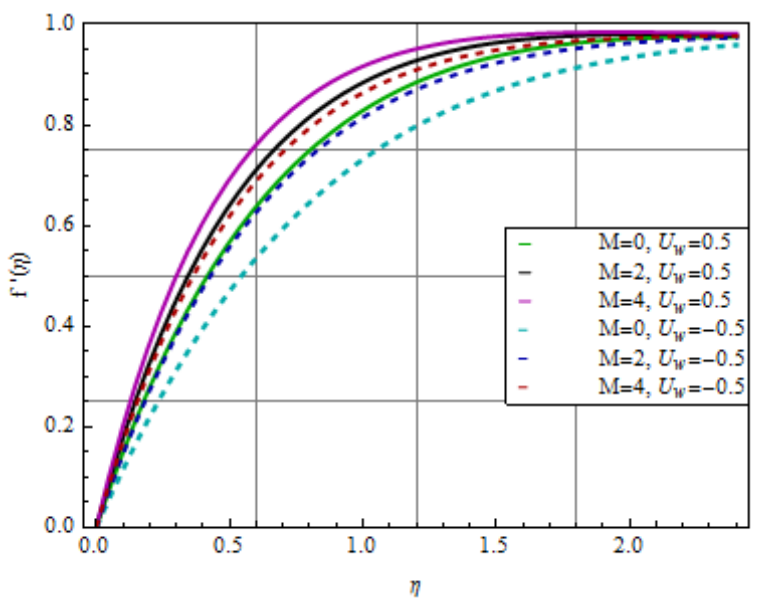

Fig. 13: The velocity distribution for alumina-sodium alginate nanofluid for different values of magnetic and wall transpiration parameters with $A=0.5, \varepsilon=0, \lambda=1, \operatorname{Pr}=6.2, \phi=0.2$.

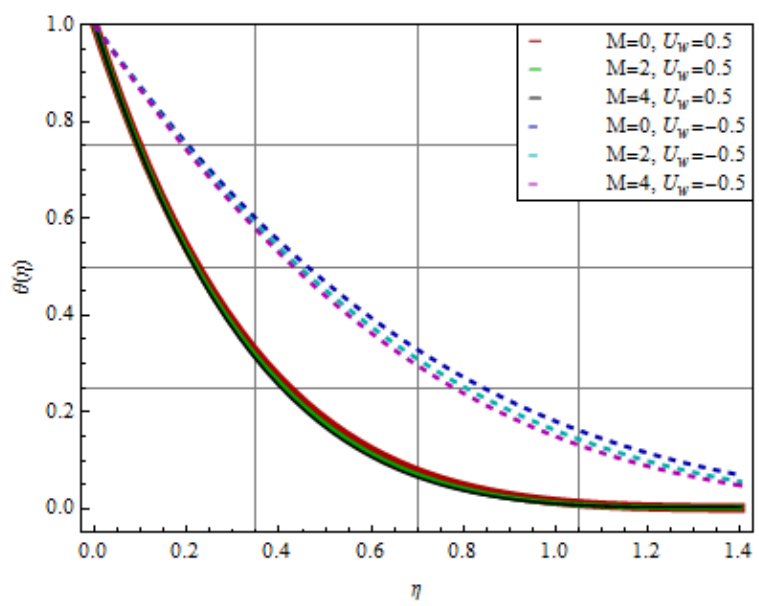

Fig. 14: The temperature distribution for alumina-sodium alginate nanofluid for different values of magnetic and wall transpiration parameters with $A=0.5, \varepsilon=0, \lambda=1, \operatorname{Pr}=6.2, \phi=0.2$.

$\begin{array}{ll}G r_{y} & \begin{array}{l}\text { local Grashof number } \\ k\end{array} \\ M & \text { thermal conductivity } \\ N u_{y} & \text { magnetic parameter } \\ \mathrm{Pr} & \text { local Nusselt number } \\ Q_{w} & \text { surface heat flux } \\ R e_{y} & \text { local Reynold number } \\ T & \text { nanofluid temperature } \\ T_{0} & \text { characteristic temperature } \\ T_{\infty} & \text { ambient temperature } \\ T_{w}(y, t) & \text { surface temperature } \\ u, v & \text { velocity component } \\ U_{w} & \text { wall surface transpiration parameter } \\ U_{w}^{\star} & \text { uniform surface mass flux }\end{array}$

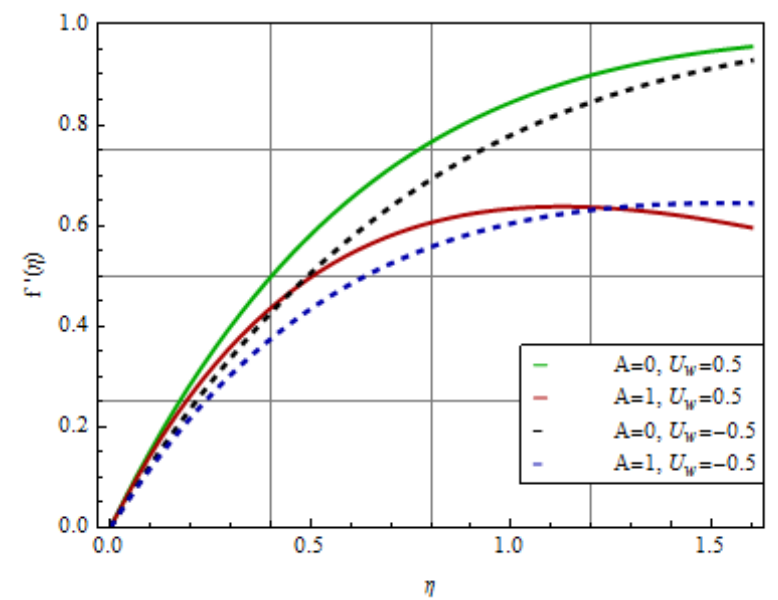

Fig. 15: The velocity distribution for alumina-sodium alginate nanofluid for different values of unsteadiness and wall transpiration parameters with $M=1, \varepsilon=0, \lambda=1, \operatorname{Pr}=6.2, \phi=0.2$.

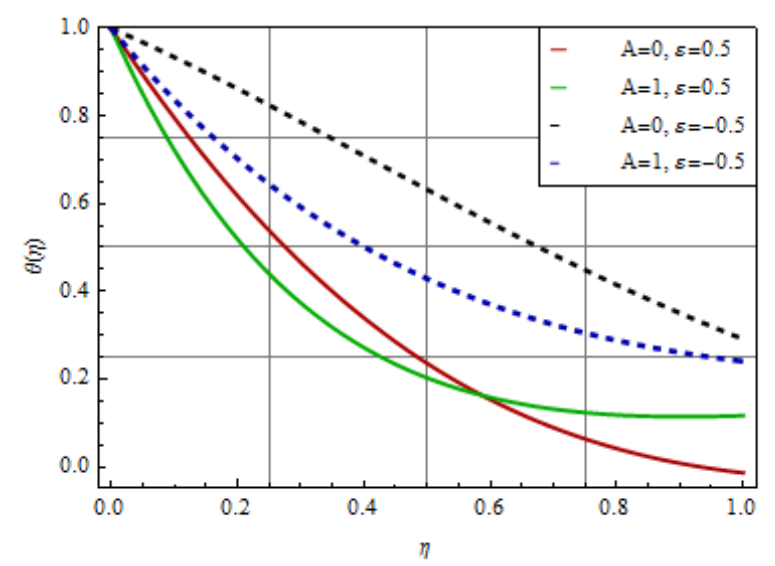

Fig. 16: The temperature distribution for alumina-sodium alginate nanofluid for different values of unsteadiness and wall transpiration parameters with $M=1, \varepsilon=0, \lambda=1, \operatorname{Pr}=6.2, \phi=0.2$.

$\begin{array}{ll}V_{\infty}(y, t) & \text { free stream velocity } \\ v_{w}(y, t) & \text { surface velocity } \\ x, y & \text { Cartesian coordinates } \\ \text { Greek symbols } \\ \alpha & \text { thermal diffusivity } \\ \beta & \text { thermal expansion coefficient } \\ \eta & \text { similarity variable } \\ \lambda & \text { mixed convection parameter } \\ \mu & \text { dynamic viscosity } \\ \phi & \text { nanoparticle volume fraction } \\ \psi & \text { stream function } \\ \rho & \text { fluid density } \\ \sigma & \text { electrical conductivity } \\ \tau_{w} & \text { wall shear stress } \\ \theta(\eta) & \text { dimensionless temperature }\end{array}$


$v$

$\varepsilon$

subsccripts

$\infty \quad$ ambient condition

f base fluid

nf nanofluid

$s \quad$ solid nanoparticle

$w \quad$ condition at the surface of wedge

\section{supersccripts}

, prime denotes the derivative with respect to $\eta$

\section{References}

[1] S.U.S. Choi and E.A. Eastman, Enhancing thermal conductivity of fluids with nanoparticles, The Proceedings of ASME International Mechanical Engineering Congress and Exposition San, Francisco, USA, 1995.

[2] S.U.S. Choi, Z.G. Zhang, W.Yu, F.E. Lockwood, E.A. Grulke, Anomalously thermal conductivity enhancement in nanotube suspensions, Appl. Phys. Lett. 79 (2001) 2252-2254.

[3] Y. Xuan and Q. Li, Heat transfer enhancement of nanofluids, Int. J. Heat Fluid Flow 21 (2000) 58-64.

[4] J.A. Eastman, S.U.S. Choi, S. Li, W. Yu, L. J. Thompson, Anomalously increased effective thermal conductivities of ethylene glycol-based nanofluids containing copper nanoparticles, Appl. Phys. Lett. 78 (2001) 718-720.

[5] H.E. Patel, S.K. Das, T. Sundarrajan, A.S. Nair, B. George, T. Pradeep, Thermal conductivities of naked and monolayer protected metal nanoparticle based nanofluids: Manifestation of anomalous enhancement and chemical effects, Appl. Phys. Lett. 83 (2003) 2931-2933.

[6] D.W. Zhou, Heat transfer enhancement of copper nanofluid with acoustic cavitation, Int. J. Heat Mass Transfer 47 (2004) 3109-3117.

[7] K. Hiemenz, Die grenzschicht an einem in den gleichformigen Flussigkeitsstrom eingetauchten graden Kreiszylinder, Dinglers Polytechnisches J.326 (1911) 321-331.

[8] W.K. Garg and K.R. Rajagopal, Stagnation-point flow of a nonnewtonian fluid, Mechancis Research Communicaiton 17(6) (1990) 415-421.

[9] C.Y. Wang, Stagnation flow towards a shrinking sheet, Int. J. of Non-Linear Mech. 43(5) (2008) 377-382.

[10] M. Awais, T. Hayat, M. Mustafa, K. Bhattacharyya, M. A. Farooq, Analytic and numeric solutions for stagnation-point flow with melting, thermal-diffusion and diffusion-thermo effects. International Journal of Numerical Methods Heat Fluid Flow 24(2) (2014) 438-454

[11] T. Hayat, Z. Iqbal, M. Mustafa, A. Alsaedi, Stagnation-point flow of Jeffrey fluid with melting heat transfer and Soret and Dufour effects, International Journal of Numerical Methods for Heat and Fluid Flow 24(2) (2014) 402-418.

[12] N. Ramachandran, T.S. Chen and B.F. Armaly, Mixed convection in stagnation flows adjacent to a vertical surface, ASME Journal of Heat Transfer 110 (1988) 373-377.

[13] C.D.S. Devi, H.S. Takhar, G. Nath, Unsteady mixed convection flow in stagnation region adjacent to a vertical surface, Heat and Mass Transfer 26(2) (1991) 71-79.

[14] A. Ishak, R. Nazar, I. Pop, Mixed convection on the stagnation point flow toward a vertical, continuously stretching sheet. ASME Journal of Heat Transfer 129(8) (2007) 1087-1090.

[15] O.D. Makinde, W.A. Khan and Z.H. Khan, Buoyancy effects on MHD stagnation point flow and heat transfer of a nanofluid past a convectively heated stretching/shrinking sheet, Internatinal Journal of Heat and Mass Transfer 62 (2013) 526-533.

[16] H. Tamim, S. Dinarvand, R. Hosseini, I. Pop, MHD mixed convection stagnationpoint flow of a nanofluid over a vertical permeable surface: a comprehensive report of dual solutions, Heat and Mass Transfer 50(5) (2014) 639-650.

[17] O.A. Bég, H.S. Takhar, R. Bhargava, S. Rawat, V.R. Prasad, Numerical study of heat transfer of a third grade viscoelastic fluid in non-Darcy porous media with thermophysical effects, Phys. Scr. 77 (2008) 1-11.

[18] H. Jin, N. Phan-Thien and R.I. Tanner, An explicit finite volume method for viscoelastic fluid flows, Comput. Mech. 13 (1994) 443-457.

[19] M.M. Rashidi and D.D. Ganji, Homotopy perturbation combined with Padé approximation for solving two-dimensional viscous flow in the extrusion process, Int. J. Nonlinear Sci. 7 (2009) 387-394.

[20] S. Ghafoori, M. Motevalli, M.G. Nejad, F. Shakeri, D.D. Ganji, M. Jalaal, Efficiency of differential transformation method for nonlinear oscillation: comparison with HPM and VIM, Curr. Appl. Phys. 11 (2011) 965-971.

[21] J.H. He, Variational iteration method-a kind of non-linear analytical technique: some examples, Int. J. Nonlin. Mech. 34 (1999) 699-708.

[22] O.A. Bég, T.A. Bég, H.S. Takhar, A. Raptis, Mathematical and numerical modeling of non-Newtonian thermo-hydrodynamic flow in non-Darcy porous media, Int. J. Fluid Mech. Res. 31 (2004) 1-12.

[23] A.M. Lyapunov, The General Problem of the Stability of Motion, Int. J. of control 55 (1992) 531-534.

[24] A.V. Karmishin, A.I. Zhukov and V.G. Kolosov, Methods of Dynamics Calculation and Testing for Thin-Walled Structures, Mashinostroyenie Moscow, 1992.

[25] G. Adomian, Solving Frontier Problems of Physics: The Decomposition Method, Kluwer Academic Publishers, Boston, 1994.

[26] S.J. Liao, Beyond Perturbation: Introduction to the Homotopy Analysis Method, Chapman and Hall/CRC Press, Boca Raton Fla 2003.

[27] H. Xu , S.J. Liao, I. Pop, Series solutions of unsteady threedimensional MHD flow and heat transfer in the boundary layer over an impulsively stretching plate, Euro. J. Mech. B-Fluids 26 (2007) 15-27.

[28] M.M. Rashidi, G. Domairry, S. Dinarvand, Approximate solutions for the Burger and regularized long wave equations by means of the homotopy analysis method, Commun. Nonlinear Sci. Numer. Simul. 14 (2009) 708-717.

[29] Z. Ziabakhsh, G. Domairry, Solution of the laminar viscous flow in a semi-porous channel in the presence of a uniform magnetic field by using the homotopy analysis method, Commun. Nonlinear Sci. Numer. Simul. 14 (2009) 1284-1294.

[30] Y.Y. Lok, I. Pop, D.B. Ingham, N. Amin, Mixed convection flow of a micropolar fluid near a non-orthogonal stagnation-point on a stretching vertical sheet, International Journal of Numeri- 
cal Methods for Heat and Fluid Flow 19(3-4) (2009) 459-483.

[31] R.J. Tiwari and M.K. Das, Heat transfer augmentation in a twosided lid-driven differentially heated square cavity utilizing nanofluids, International Journal of Heat and Mass Transfer 50(9-10) (2007) 2002-2018.
[32] H.F. Oztop and E. Abu-Nada, Numerical study of natural convection in partially heated rectangular enclosures filled with nanofluids, International Journal of Heat and Fluid Flow 29(5) (2008) 1326-1336. 